\title{
Инновационно сориентированная цифровая инфраструктура - сфера обеспечения успешной реализации технологического рывка
}

\author{
Вавилина А.В. ${ }^{1}$ К Калашников И.Б. ${ }^{2}$, Гладышева И.В. ${ }^{1}$ \\ ${ }^{1}$ Российский университет дружбы народов, Москва, Россия \\ ${ }^{2}$ Саратовский социально-экономический институт (филиал) РЭУ им. Г.В. Плеханова, Саратов, Россия
}

\section{АННОТАЦИЯ:}

Инновационно сориентированная инфраструктура рассматривается как элемент экономической системы, особая ее подсистема, активизирующая инновационную деятельность субъектов - реализаторов технологического рывка; как особая благоприятная среда, оказывающая услуги по сбору и анализу данных для целей заказчика и поставщика с учетом роста их экономической ценности, гармонизирующая их хозяйственные взаимосвязи, обеспечивающие становление нового типа экономики. Выделены и проанализированы структурные элементы инновационно сориентированной инфраструктуры. Представлены доказательства для признания такой инфраструктуры в качестве одного из важнейших инструментов реализации инновационной политики, направленной на получение результатов технологических преобразований в виде надежно функционирующей цифровой экономики. Доказано, что цифровизирующаяся инфраструктура способна адаптироваться к новым условиям социально-экономической системы, выступать в качестве особого способа насыщения экономики цифровыми ресурсами и в этом своем качестве обеспечивать технологический рывок, оказывать стимулирующее влияние на все сферы хозяйствования, на общие экономические процессы. Приведены доводы, объясняющие последствия деятельности субъектов инфраструктуры по обработке и использованию данных в виде возникновения качественно новых социально-экономических отношений.

КЛЮЧЕВЫЕ СЛОВА: инновационно сориентированная инфраструктура, цифровая инфраструктура, цифровые технологии, технологический рывок, цифровая экономика, цифровые ресурсы, цифровизация, цифровой сектор, цифровой потенциал.

\section{Innovatively oriented digital infrastructure - the sphere of ensuring successful implementation of technological breakthrough}

\section{Vavilina A.V. ${ }^{1}$, Kalashnikov I.B. ${ }^{2}$, Gladysheva I.V. ${ }^{1}$}

${ }^{1}$ RUDN University, Russia

${ }^{2}$ Saratov Socio-Economic Institute of Plekhanov Russian University of Economics, Russia

\section{Введение}

П ля успешного выхода России на лидирующие позиции в мировом экономическом пространстве в Послании Президента Федеральному собранию 2018 г. поставлена задача осуществления технологического рывка [1], результатом которого должна стать цифровая 
экономика. Процесс цифровизации экономики предполагает фундаментальные изменения в области собственно технологии, производственных процессах и общественной жизни. Массовое применение цифровых технологий выражается в качественных изменениях в бизнес-моделях, характере ведения бизнеса, его управляемости и гибкости. Наибольшее воздействие на становление цифровой экономики оказывают технологии искусственного интеллекта, технотронные источники четвертого поколения, интернет вещей, облачные вычисления, «аналитика больших данных», робототехника, производство продукции и 3D-печати, автономные транспортные средства, социальные сети и другие виды цифровых интернет-платформ.

Решение задач расширенного применения цифровых технологий предполагает наличие благоприятной среды - специальной, поддерживающей становление нового типа экономики, инфраструктуры, выстроенной в соответствии с решаемыми задачами. Как элемент экономической системы, особая ее подсистема инфраструктура в ранге благоприятной среды для становления и развития цифровой экономики форми-

\begin{abstract}
:
Innovatively oriented infrastructure is considered as the element of the economic system, its special subsystem, which activates the innovation activity of the subjects - implementers of the technological breakthrough; as the special enabling environment, providing services for the collection and analysis of data for the purposes of the customer and supplier, taking into account the growth of their economic value, harmonizing their economic interrelations that ensure the emergence of a new type of economy. Structural elements of the innovation-oriented infrastructure have been singled out and analyzed. Evidence is presented for the recognition of such an infrastructure as one of the most important tools for implementing innovation policies aimed at obtaining the results of technological transformations in the form of a reliably functioning digital economy. It is proved that the digitalizing infrastructure is able to adapt to the new conditions of the social and economic system, to act as a special way of saturating the economy with digital resources and, in this capacity, to provide the technological leap, to exert the stimulating influence on all spheres of management, and on general economic processes. The arguments explaining the consequences of the activities of the infrastructure subjects on the processing and use of data in the form of the emergence of qualitatively new socio-economic relations are presented.
\end{abstract}

KEYWORDS: innovation-oriented infrastructure, digital infrastructure, digital technologies, technological leap, digital economy, digital resources, digitalization, digital sector, digital potential.

JEL Classification: 031, 032, 033

Received: 24.07.2018 / Published: 30.09.2018

(C) Author(s) / Publication: CREATIVE ECONOMY Publishers

For correspondence: Vavilina A.V (vavilina_avapfur.ru)

\title{
CITATION:
}

Vavilina A.V. Kalashnikov I.B., Gladysheva I.V. (2018) Innovatsionno sorientirovannaya tsifrovaya infrastruktura - sfera obespecheniya uspeshnoy realizatsii tekhnologicheskogo ryvka [Innovatively oriented digital infrastructure - the sphere of ensuring successful implementation of technological breakthrough]. Voprosy innovatsionnoy ekonomiki. 8. (3). - 349-364. doi: 10.18334/vinec.8.3.39423 
руется при регулировании инновационного процесса и активизации инновационной деятельности. Особое значение она приобретает при наличии высокого уровня технических, производственных, финансовых, коммерческих и других рисков.

Исследование такой инновационно сориентированной, цифровой инфраструктуры есть установление содержания ее устройства, которое способно обеспечить техникотехнологическое развитие электронной промышленности и IT-технологий, осуществление профессиональных компетенций субъектами и институтами, входящими в ее структуру. Более глубокое познание инновационно сориентированной инфраструктуры предполагает уточнение направлений снижения рисков, возникающих в ходе перевода экономики на новую технологическую базу с целью формирования цифровой экономики, обеспечения ее инновационных и конкурентных преимуществ.

\section{Методология исследования}

Методологической основой исследования инновационно сориентированной, цифровой инфраструктуры принято положение о том, что это инфраструктура национальной инновационно выстроенной системы. Она представляет собой совокупность юридических лиц, организаций и институтов, обеспечивающих материально-техническое, финансовое, организационно-методическое, информационное, консультационное и иное обслуживание инновационной деятельности субъектов и поддержание их инновационной активности. Анализ данной совокупности был выстроен в соответствии с системно-функциональным подходом, позволяющим выявить качества, свойства, последствия ее системного действия по созданию возможностей осуществления технологического рывка в направлении формирования цифровой экономики, обеспечения использования ресурсного и кадрового потенциала для достижения поставленных целей. Использование воспроизводственного подхода применялось для выявления логики экономических процессов, обеспечивающих непрерывность технико-технологических изменений в системе воспроизводства на основе новых открытий и изобретений. В соответствии с формационным подходом анализировались основные технологические сдвиги в ходе смены стадий экономической формации, выявлялись их

\section{ОБ АВTOPAX:}

Вавилина Алла Владимировна, кандидат экономических наук, доцент кафедры менеджмента экономического факультета (vavilina_avapfur.ru)

Калашников Игорь Борисович, доктор экономических наук, профессор кафедры экономической безопасности (Igor Kalashnikov1965amail.ru)

Гладышева Ирина Валерьевна, кандидат экономических наук, доцент кафедры менеджмента экономического факультета (Gladysheva_ivarudn.university)

\section{ЦИТИРОВАТЬ СТАТЬЮ:}

Вавилина А.В, Калашников И.Б., Гладышева И.В. Инновационно сориентированная цифровая инфраструктура - сфера обеспечения успешной реализации технологического рывка // Вопросы инновационной экономики. - 2018. - Том 8. - № 3. - С. 349-364. doi: 10.18334/vinec.8.3.39423 
причины и последствия, определялись меры для сглаживания возникающих рисков и угроз.

\section{Результаты исследования}

Технологической рывок по своей сути есть фундаментальное, ускоренными темпами совершающееся переустройство технологической базы существующей экономики на основе использования инноваций, технических достижений, профессиональных компетенций субъектов и институтов с целью формирования цифровой экономики, обеспечения ее инновационных и конкурентных преимуществ.

Логику осуществления технологического рывка можно представить следующим образом (рис. 1):

Такая логика свидетельствует о необходимости тесной взаимосвязи процессов развития экономической системы и ее инфраструктуры, о едином, целостном процессе, способном обеспечить переход к новому технологическому укладу. Вместе с тем для успешного без срывов прохождения ступеней осуществления технологического рывка необходимо не просто наличие в рамках общей экономической системы развитой инфраструктуры, а инновационно сориентированной, цифровой по содержанию, имеющей мощный потенциал развития, четко организованной и адекватно сориентированной, целенаправленной инфраструктуры - инфраструктуры, адекватной выстраивающейся цифровой экономике (рuс. 2).

В определенном смысле такая по качественным характеристикам инфраструктура, как цифровая, инновационно сориентированная, она в экономической системе выполняет ряд важных функций (рuс. 3).
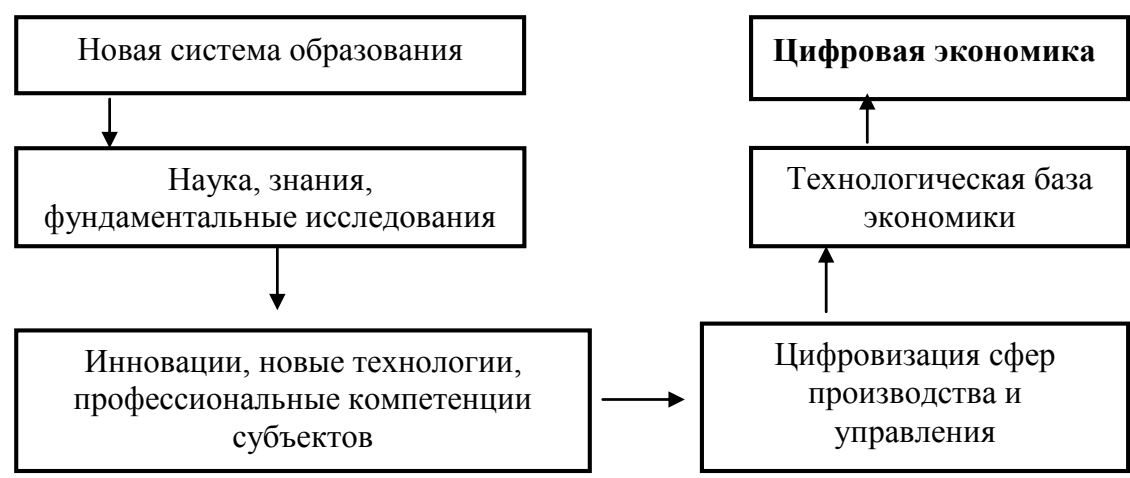

Инновационная экономическая система

Рисунок 1. Логика осуществления технологического рывка Источник: составлено авторами 
Инфраструктура цифровой экономики

- сложная по структуре;

- многоаспектная по направлениям деятельности;

- инновационная по содержанию;

- цифровизированная по качественным характеристикам;

- $\quad$ эффективная по последствиям и результатам действиям

Рисунок 2. Характеристика цифровой инфраструктуры Источник: составлено авторами

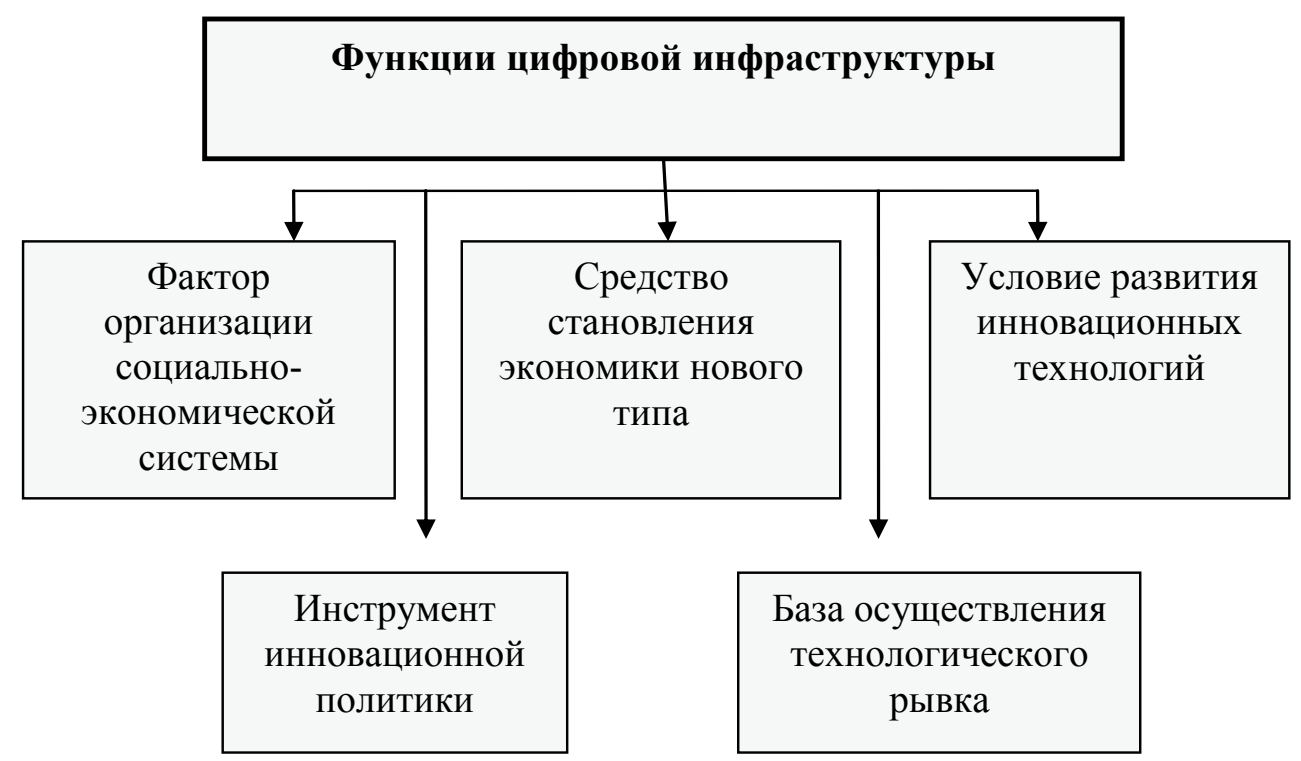

Рисунок 3. Функции цифровой инфраструктуры Источник: составлено авторами 
Инновационно сориентированная цифровая инфраструктура включает все информационные, организационные, маркетинговые, образовательные, сетевые и другие институты, которые помогают новой инновационной идее добираться до своей практической реализации и находить своего потребителя. По своему масштабу инфраструктура весьма значительна. Она занимает часть (если не большую) экономической системы страны. Поэтому цифровизация инфраструктуры есть цифровизация экономики в целом.

К цифровой инфраструктуре относятся предприятия и организации, перешедшие к «цифре», производящие инновационное благо, работающие в отраслях производства, торговли, связи, в сфере транспорта, управления, планирования, оптимизации экономических процессов.

Мировая практика свидетельствует о том, что чем содержательнее инфраструктура, чем успешнее она развивается, чем выше степень влияния используемых данных на практику хозяйствования, тем выше уровень согласованности и соответствия системы экономики и ее инфраструктуры (табл. 1).

Следует отметить, что, если сравнивать качество инфраструктуры России с подобным показателем в странах, которые имеют схожий уровень благосостояния населения (Польша, Венгрия, Греция, Казахстан), то уровень качества инфраструктуры будет сопоставим. В целом международные оценки качества ключевой российской инфраструктуры свидетельствуют о том, что общая инфраструктура российской экономики на сегодняшний момент не адекватна задачам модернизации экономики, а тем более перехода ее на инновационный путь развития.

Таблица 1

Рейтинг качества инфраструктуры в странах с разным уровнем дохода и удельные веса трех групп факторов в общей оценке конкурентоспособности

\begin{tabular}{|l|c|c|c|c|c|}
\hline \multicolumn{1}{|c|}{ Страна } & \multirow{2}{*}{$\begin{array}{c}\text { Качество инфра- } \\
\text { структуры (позиция в }\end{array}$} & Удельный BBП (те- & \multicolumn{2}{|c|}{ Фущие цены USD) } \\
\cline { 4 - 6 } & рейтинге) & & базовые & эффективности & инновации \\
\hline Швейцария & 1 & 81332 & 20 & 50 & 30 \\
\hline Гонконг & 2 & 37777 & 20 & 50 & 30 \\
\hline ОАЭ & 3 & 43876 & 21,2 & 50 & 28,8 \\
\hline Финляндия & 4 & 47129 & 20 & 50 & 30 \\
\hline Сингапур & 5 & 54776 & 20 & 50 & 30 \\
\hline Нидерланды & 6 & 47634 & 20 & 50 & 30 \\
\hline Австрия & 7 & 64863 & 20 & 50 & 30 \\
\hline Исландия & 8 & 45536 & 20 & 50 & 30 \\
\hline Япония & 9 & 38491 & 20 & 50 & 30 \\
\hline Франция & 10 & 43000 & 20 & 50 & 30 \\
\hline
\end{tabular}

Источник: [9] (Mokhamad Arif Salim, 2015) 
Таблица 2

Динамика позиций Российской Федерации в GII-2017: 2015-2017 гг.

\begin{tabular}{|c|c|c|c|c|}
\hline Год & $\begin{array}{c}\text { GII } \\
\text { (место } \\
\text { в рейтинге) }\end{array}$ & Pесурсы инноваций & Результаты инноваций & Эффективность инноваций \\
\hline 2017 & 45 & 43 & 51 & 75 \\
\hline 2016 & 43 & 44 & 47 & 69 \\
\hline 2015 & 48 & 52 & 49 & 60 \\
\hline
\end{tabular}

Источник: по данным: GII-2017: как инновации кормят мир и Россию // ИСИЭЗ НИУ ВШЭ.

В мировом рейтинге 2017, по данным Всемирного экономического форума (ВЭФ), Россия занимает 35 место. Оценка инфраструктуры России выше, чем в африканских и латиноамериканских странах, но значительно уступает европейским странам и Северной Америке.

Одним из ключевых элементов инновационной инфраструктуры как национальной, так и межгосударственной являются цифровые информационные ресурсы и системы, содержащие информацию о результатах инновационной деятельности, продуктах, услугах, технологиях, научных и инновационных организациях, объектах интеллектуальной собственности, процессах трансфера технологий.

Эффективность информационного компонента инновационной инфраструктуры прямо или косвенно проявляется в мультипликации приложения научно-технических результатов и комплексном подходе к использованию инвестиций и инноваций в научно-промышленной сфере [2] (Biktimirov, Syuntyurenko, 2017), отражается в общем уровне конкурентоспособности страны (табл. 2).

Информационно-технологические системы и соответствующие службы, которые основаны на базах данных, содержащих разную информацию о субъектах и результатах их инновационной деятельности, являются ключевыми элементами инновационно сориентированной инфраструктуры в России, как и в других странах. Сюда включается информация об инновационных продуктах, услугах, технологиях, научных и инновационных организациях, объектах интеллектуальной собственности и т. п. К таким системам относятся следующие: CORDIS (с 1990 г.) - система баз данных, в которой аккумулируется информация об исследовательской деятельности в странах ЕС. Инновационные организации этой системы могут не только рекламировать результаты своих собственных НИОКР, но и оказывать самую разную информационную помощь; научно-технологическая информационная служба ARIST, являющаяся информационным инструментом для получения сведений о существующих рынках инновационных технологиях, которая используется для предоставления ряда информационных услуг, для установления контактов инновационных организаций с потенциальными клиентами; Европейская система патентной информации и документации EPIDOS, японская база данных PATOLIS - источник данных о японских патентах. 
Эти и другие системы «открывают ворота к мировой научно-технической информации». Среди российских организаций, развивающих информационно-технологические системы с целью предоставления информации об инновационных технологиях, выделяются Всероссийский институт научно-технической информации (ВИНИТИ), Всероссийский научно-технический информационный центр (ВНТИЦ) и др.

Успешное развитие цифровой инфраструктуры эксперты разных стран связывают с интеграционными процессами, которые в новых условиях позволят достичь синергетического эффекта за счет объединения и координации действия различных элементов инфраструктуры. Примером такой интеграции стало создание Европейской сети инновационных и бизнес-центров - EBN. Данная сеть была создана в 1984 г. В настоящее время Европейская сеть включает 160 инновационных и бизнес-центров из 21 страны и 70 ассоциированных членов, которые разделяют цель содействия и развития малых и средних предприятий [7].

Инновационно сориентированная, цифровая инфраструктура предстает своеобразной системной основой выстраивания всей социально-экономической жизни общества. При этом, она выступает важным специфическим элементом общей экономической системы, действенным инструментом ее регулирования и управления, является сложно выстроенным системным образованием и включает свои специфические подсистемы (табл. 3).

Все перечисленные подсистемы в соответствии со своим содержанием предназначены для решения специфических задач и имеют свойственные им последствия. Во всей совокупности своих подсистем инфраструктура предназначена для решения задач выстраивания экономики нового типа - цифровой экономики, для перехода к новому технологическому укладу. К таким задачам относятся: 1) информационное обеспечение происходящих экономических процессов и совершающихся изменений; 2) обеспечение роста экономической ценности в области передачи, обработки и хранения данных; 3) производственно-технологическая и финансовая поддержка инновационной деятельности; 4) сертификация и стандартизация инновационной продукции; 5) содействие продвижению эффективных разработок и реализации инновационных проектов; 6) проведение выставок инновационных проектов и продуктов; 7) оказание практической и консультационной помощи в деле подготовки и переподготовки, повышения квалификации кадров для инновационной деятельности.

Свое предназначение цифровая инфраструктура реализует через специальные компании и институты, которые призваны обеспечивать экономику цифровыми ресурсами. В первую очередь она способна оказывать услуги по сбору и анализу данных для целей заказчика с учетом роста их экономической ценности, гармонизировать взаимосвязи между основными типами рынков, определяющими эффективность функционирования инновационной системы: рынки инноваций как объектов интеллектуальной собственности; рынки инновационного капитала и ценных бумаг высокотехнологических компаний; рынки инновационной продукции; рынки услуг по под- 
Таблиияа 3

\section{Структурные элементы инновационно сориентированной цифровой инфраструктуры}

\begin{tabular}{|l|l|}
\hline \multicolumn{1}{|c|}{$\begin{array}{c}\text { Подсистемы } \\
\text { инфаструктуры }\end{array}$} & \multicolumn{1}{|c|}{ Элементы отдельных подсистем инфраструктуры } \\
\hline $\begin{array}{l}\text { материальная (произ- } \\
\text { водственно-технологи- } \\
\text { ческая) }\end{array}$ & $\begin{array}{l}\text { технопарки, инвестиционно-технологические центры, бизнес-инку- } \\
\text { баторы, центры трансферта, технологий и т. п. }\end{array}$ \\
\hline финансовая & различные типы финансовых фондов и финансовых институтов \\
\hline социальная & $\begin{array}{l}\text { институты, организации, центры культуры, досуга, здравоохранения, } \\
\text { образования, связи, транспорта и т. д. }\end{array}$ \\
\hline информационная & $\begin{array}{l}\text { собственные базы данных, знаний и центры доступа, а также } \\
\text { аналитические; статистические, информационные центры (то есть } \\
\text { организации, оказывающие услуги) }\end{array}$ \\
\hline кадровая & $\begin{array}{l}\text { образовательные учреждения по подготовке и переподготовке ка- } \\
\text { дров в области научного и инновационного менеджмента, техноло- } \\
\text { гического аудита, маркетинга и т. д. }\end{array}$ \\
\hline $\begin{array}{l}\text { экспертно-консалтин- } \\
\text { говая }\end{array}$ & $\begin{array}{l}\text { организации, занятые оказанием услуг по проблемам интеллекту- } \\
\text { альной собственности, стандартизации и сертификации; центры как } \\
\text { общего, так и специализирующиеся в отдельных сферах (финан- } \\
\text { сов, инвестиций, маркетинга, управления и т. д.) консалтинга. Их } \\
\text { деятельность по обработке и использованию данных имеет своим } \\
\text { следствием возникновение качественно новых социально-экономи- } \\
\text { ческих отношений }\end{array}$ \\
\hline $\begin{array}{l}\text { организационно-мето- } \\
\text { дическая }\end{array}$ & $\begin{array}{l}\text { потенциал данных, полученных на основе цифровых технологий, } \\
\text { маркетинговых, статистических исследований, практики построения } \\
\text { моделей ведения бизнеса, научных и социальных сетей, коопераци- } \\
\text { онных связей между субъектами инновационной системы }\end{array}$ \\
\hline
\end{tabular}

Источник: составлено авторами

держке и сопровождению инновационной деятельности. Успешное гармонизирующее влияние инфраструктуры совершается тогда, когда сама инфраструктура становится и действует как важнейший фактор становления цифровой экономики во всей совокупности его составляющих в виде единого, системно действующего, результативного целого (табл. 4).

Без успешно развивающейся инновационно сориентированной инфраструктуры невозможно осуществить так необходимый России технологический рывок, обеспечить эффективное функционирование всей инновационной системы.

По данным Росстата, удельный вес организаций, осуществляющих технологические инновации, снижается как в целом по России, так и по отдельным регионам (таблица 5).

Текущее состояние российской инфраструктуры характеризуется наличием ряда проблем, сдерживающих обеспечение прогресса в области цифровых технологий и цифровизации экономических процессов. 
Таблиияа 4

Характеристика инновационно сориентированной цифровой инфраструктуры, как фактора становления цифровой экономики

\begin{tabular}{|l|l|}
\hline $\begin{array}{l}\text { Составные элементы } \\
\text { фактора }\end{array}$ & \multicolumn{1}{|c|}{ Содержание и последствия действия составных элементов фактора } \\
\hline $\begin{array}{l}\text { цифровые техноло- } \\
\text { гии и цифровизация }\end{array}$ & $\begin{array}{l}\text { содействуют формированию фундаментальных признаков общества } \\
\text { нового типа, цифровых моделей технологических и экономических про- } \\
\text { цессов, автоматизации процесса принятия управленческих решений }\end{array}$ \\
\hline $\begin{array}{l}\text { данные, их досто- } \\
\text { верность }\end{array}$ & $\begin{array}{l}\text { создают условия для планирования и прогнозирования экономических } \\
\text { процессов на всех уровнях хозяйствования, для достоверной оценки } \\
\text { результатов деятельности субъектов и институтов, оптимизации исполь- } \\
\text { зования всех видов ресурсов }\end{array}$ \\
\hline $\begin{array}{l}\text { сеть передачи } \\
\text { данных }\end{array}$ & $\begin{array}{l}\text { обеспечивает связь между различными сферами хозяйства, а потому } \\
\text { может оказывать влияние на формирование нового по содержанию } \\
\text { экономического пространства }\end{array}$ \\
\hline $\begin{array}{l}\text { электронная } \\
\text { промышленность- } \\
\text { элемент цифрового } \\
\text { сектора }\end{array}$ & $\begin{array}{l}\text { на основе инновационных технологий производит микрочипы, ком- } \\
\text { пьютеры, телекоммуникационные устройства, электронику бытового }\end{array}$ \\
\hline $\begin{array}{l}\text { компании цифрово- } \\
\text { го сектора }\end{array}$ & $\begin{array}{l}\text { становятся точками роста формирующейся цифровой экономики, ока- } \\
\text { зывают услуги в области цифровых технологий, используют цифровые } \\
\text { средства производства, хранения, управления данными }\end{array}$ \\
\hline $\begin{array}{l}\text { цифровой потенци- } \\
\text { ал фирмы }\end{array}$ & $\begin{array}{l}\text { обеспечивает рентабельность использования цифровых ресурсов, } \\
\text { необходимый уровень трансакционных издержек, организационную } \\
\text { эффективность, рыночные перспективы }\end{array}$ \\
\hline
\end{tabular}

Источник: составлено авторами

Таблицза 5

Удельный вес организаций, осуществлявших технологические инновации в отчетном году, в общем числе обследованных организаций, по субъектам Российской Федерации, \%

\begin{tabular}{|l|l|l|l|l|l|l|l|}
\hline & \multicolumn{1}{|c|}{2010} & \multicolumn{1}{|c|}{2011} & \multicolumn{1}{|c|}{2012} & \multicolumn{1}{|c|}{2013} & \multicolumn{1}{c|}{2014} & \multicolumn{1}{c|}{2015} & \multicolumn{1}{c|}{2016} \\
\hline Российская Федерация & 7,9 & 8,9 & 9,1 & 8,9 & 8,8 & 8,3 & 7,3 \\
\hline Центральный федеральный округ & 7,3 & 8,8 & 9,7 & 9,6 & 9,8 & 9,8 & 9,0 \\
\hline Северо-Западный федеральный округ & 7,6 & 9,5 & 9,5 & 9,2 & 8,9 & 8,1 & 7,1 \\
\hline Южный федеральный округ & 6,2 & 5,3 & 6,3 & 6,2 & 6,6 & 6,7 & 6,2 \\
\hline Северо-Кавказский федеральный округ & 5,0 & 4,2 & 5,6 & 5,3 & 5,8 & 4,4 & 2,6 \\
\hline Приволжский федеральный округ & 10,2 & 11,2 & 10,8 & 10,4 & 10,4 & 9,5 & 8,4 \\
\hline Уральский федеральный округ & 9,6 & 9,8 & 9,0 & 8,0 & 7,1 & 6,7 & 6,5 \\
\hline Сибирский федеральный округ & 6,8 & 7,6 & 7,7 & 8,2 & 7,9 & 7,2 & 6,0 \\
\hline Дальневосточный федеральный округ & 7,0 & 9,6 & 9,6 & 8,3 & 7,9 & 6,5 & 5,7 \\
\hline
\end{tabular}

Источник: составлено авторами на основе данных Росстата 
Малые и средние инновационные компании крайне недостаточно интегрированы в инновационные сети; недостаточно развиты и кооперационные связи, позволяющие, находясь в своей лучшей форме, формировать инновационные цепочки «наука и образование - инновационный малый и средний бизнес - крупный бизнес». Это препятствует распространению и капитализации знаний в российской экономике. Без разрешения этих и других проблем, без реального повышения эффективности инфраструктуры невозможн: обеспечение трансферта результатов сектора исследований и разработок в российскую, в том числе и в глобальную, экономику; развитие предпринимательства в инновационной сфере; обеспечение технологического обновления основных активов. Получение конкретных результатов активизации процессов повышения эффективности инфраструктуры требует принятия необходимых мер, в числе которых:

1) формирование единой цифровой среды, посредством доверенных сервисов идентификации и аутентификации взаимодействующих субъектов, защиты от несанкционированного доступа и модификации документов;

2) активизация скрытого потенциала экономической активности;

3) реформирование правового регулирования процессов управления информационными рисками и обеспечения кибербезопасности;

4) актуализация инновационной деятельности институтов инфраструктуры.

В структуре инновационно сориентированной инфраструктуры особо выделяются: инновационные центры и технопарки, венчурные и страховые фонды, особые предприятия и научно-производственные центры и т. д. Ключевое значение для развития новой инфраструктуры имеют технопарковые структуры разных типов, которые существуют в разных формах и в большом множестве: научные парки, парки высоких технологий, технологические и исследовательские парки, инновационные парки, инновационно-технологические, бизнес-инновационные центры, центры трансферта технологий, инкубаторы бизнеса и инкубаторы технологий, виртуальные инкубаторы, технополисы и наукограды [8] (Lyashenko, 2013). Все они подразделяются на три основные группы: инкубаторы, технопарки, технополисы, среди которых инновационные инкубаторы, являясь многофункциональными комплексами, стали основой и ядром будущих технологических парков и технополисов. Технопарки как научнопроизводственные территориальные комплексы предназначены для решения задач по формированию максимально благополучной среды для развития малых и средних наукоемких инновационных фирм-клиентов.

В Российской Федерации действуют 64 технопарка. Среди действующих и создаваемых парков 34\% являются государственными проектами, 52\% - частными и $14 \%$ имеют смешанную форму собственности [13]. Более половины технопарков расположены в Центральном, Приволжском, Уральском федеральных округах (табл. 6).

Кроме технопарков, формируются кластеры, в которых ICT-индустрия поставлена ключевым направлением. В 2010-ом году принят Федеральный закон Российской 
Таблица 6

Действующие и создаваемые технопарки в Российской Федерации, ед.

\begin{tabular}{|l|c|c|}
\hline \multicolumn{1}{|c|}{ Категория } & действует & создается \\
\hline $\begin{array}{l}\text { Технопарки, в том числе по федеральным } \\
\text { округам }\end{array}$ & 52 & 12 \\
\hline Центральный & 30 & 6 \\
\hline Приволжский & 11 & 0 \\
\hline Уральский & 7 & 1 \\
\hline Сибирский & 2 & 0 \\
\hline Северо-Западный & 1 & 2 \\
\hline Северо-Кавказский & 1 & 0 \\
\hline Дальневосточный & 0 & 2 \\
\hline Южный & 0 & 1 \\
\hline
\end{tabular}

Источник: составлено авторами по данным: www.gisip.ru

Федерации № 244-Ф3 «Об инновационном центре «Сколково». В 2016-ом году был подготовлен проект Федерального закона «О Технологической долине». В Крыму реализуется концепция создания Цифровой долины [16]. В январе 2017 года ректор МГУ заявил, что при вузе создается Национальный центр компетенций в области цифровой экономики для научных исследований и подготовки кадров. Работа ведется совместно с Федеральным исследовательским центром «Информатика и управление» РАН [17]. Также в январе 2017 года Правительство РФ создало Российский фонд развития информационных технологий [18]. Кроме того, функционирует институт развития АО «Роскоминвестфонда» [19].

Развитие технопарков, усложнение среды, благоприятно влияющей на эффективность инновационной деятельности, имеют своим следствием появление наиболее интегрированного комплексного элемента инновационной инфраструктуры - технополисов (научных городов), крупнейших современных научно-промышленных комплексов, включающих вузы, научно-исследовательские институты, жилые районы, оснащенные культурной и рекреационной инфраструктурой. Их цель - сосредоточение научных исследований в передовых и пионерских отраслях, создание благоприятной среды для развития новых наукоемких производств. Благодаря высокой насыщенности технополиса инновационно-активными организациями в нем создаются все необходимые условия для быстрой и эффективной реализации всех стадий инновационного процесса.

С развитием электронного бизнеса, интернета в хозяйственной практике используются и виртуальные инкубаторы (или «инкубаторы без стен»). Такие инкубаторы: помогают оценить коммерческий потенциал инновационного проекта - основы создания новой компании; провести соответствующие маркетинговые исследования; урегулировать отношения с материнской организацией в вопросах интеллектуальной соб- 
ственности, в разработке бизнес-планов, общей стратегии бизнеса; найти партнерские организации поставщиков и потребителей инновационной продукции. Достоинством этой формы является то, что создание такого инкубатора требует скромных инвестиций. Как отдельный вид инкубатора выделяют инновационный центр - специализированный инкубатор, в котором субъектам малого предпринимательства дается возможность разрабатывать и использовать новые технологии и другие новшества научно-инновационного характера.

Инновационная инфраструктура развивается, в первую очередь, на территориях субъектов и муниципальных образований Российской Федерации с высокой концентрацией инновационного потенциала, включая наукограды, академгородки, особые экономические зоны, закрытые административно-территориальные образования и иные виды технополисов.

Особым моментом в становлении цифровой инфраструктуры становится создание (на основе кооперации и интеграции) инновационных сетей, которые способствуют:

1) формированию региональных инновационных кластеров, обеспечивающих создание конкурентных преимуществ отдельных регионов;

2) значительному снижению отставания в уровне экологического развития;

3) созданию благоприятных условий для частно-государственного партнерства в инновационной сфере;

4) интеграции науки и образования.

\section{Заключение}

Динамично развивающаяся ситуация по формированию цифровой экономики фиксирует масштаб и сложность функционирования новой инфраструктуры. Их преодоление предполагает: а) увеличение пропускной способности каналов связи; б) расширение доступа к мобильному интернету; в) активизацию работы центров обработки данных; г) вовлечение инвестиционных ресурсов на реализацию проектов и дальнейшее поддержание работоспособности IT-систем; д) снятие проблемы кадрового обеспечения «цифровой революции»; е) стимулирование спроса у поставщиков и потребителей на передовые технологии; ж) осуществление широкой господдержки по применению цифровых технологий.

\section{ИСТОЧНИКИ:}

1. Аналитический центр при Правительстве Российской Федерации, О взаимодействии элементов инновационной инфраструктуры, 2014

2. Биктимиров М.Р., Сюнтюренко О.В. ВИНИТИ РАН Цифровые информационные ресурсы современной инновационной инфраструктуры // Науч. и техн. б-ки, 2017. - № 1.

3. Информационно-аналитический отчет «Анализ мирового опыта развития промышленности и подходов к цифровой трансформации промышленности государств - 
членов Евразийского экономического союза г. Москва. Eurasiancommission.org. [Электронный ресурс]. URL: http://www.eurasiancommission.org/ru/act/prom_i_ agroprom/dep_prom (дата обращения: 09.07.2018).

4. Информационно-технологические системы. Finance-credit.news. [Электронный pecypc]. URL: http://www.finance-credit.news/innovatsinnyiy-menedjment/ informatsionno-tehnologic Informatsionno -tehnologicheskie sistemy.

5. Яник А.А., Попова С.М. История современной России: Цифровая инфраструктура междисциплинарных исследований. - М.: Издательство Московского университета, 2014.

6. Казакова М.В., Поспелова Е.А. Качество инфраструктуры как одно из ограничений экономического роста: сравнительный анализ России и стран мира // Экономические отношения, 2017. - № 3. - doi: 10.18334/eo.7.3.38071.

7. Лукша О., Пильнов Г., Тарасова О., Яновский А. Как работать с сетями трансфера технологий / Проект EuropeAid «Наука и коммерциализация технологий», 2006

8. Ляшенко Е.А. Методологические подходы к понятию «технопарковая структура» // Issue subject Upravlenet, 2013. - № 5(45).

9. Мохамад Ариф Салим Тенденции развития инфраструктурных отраслей в условиях глобализации. Elib.fa.ru. [Электронный ресурc]. URL: http://elib.fa.ru/avtoreferat/ mohamad_diss.pdf(дата обращения: 10.07.2018).

10. Национальный Доклад об инновациях В России - 2017. Rvc.ru. [Электронный pecypc]. URL: http://www.rvc.ru/upload/iblock/c64/RVK_innovation_2017.pdf (дата обращения: 09.07.2018).

11. Послание Президента РФ В. В. Путина Федеральному собранию 2018 г

12. Рейтинг инновационных регионов. Версия 2017. Ассоциация инновационных регионов России. 2018

13. Сводная статистическая информация геоинформационной системы по технопаркам. Минпромторг России. Gisip.ru. [Электронный ресурc]. URL: http://www.gisip. $\mathrm{ru}$ (дата обращения: 10.07.2018).

14. Взаимодействие объектов инновационной инфраструктуры Санкт-Петербурга, Фонд «ЦСР», отчет по итогам сессии стратегического планирования от 6 февраля 2015

15. Щедровицкий П. Понятие инфраструктуры в контексте углубления разделения труда, Лекция в бизнес-школе «Сколково», Москва, 20 февраля 2013

16. Kommersant.ru. [Электронный peсурc]. URL: http://www.kommersant.ru/ doc/2896899.

17. Kremlin.ru. [Электронный ресурс]. URL: http://www.kremlin.ru/events/president/ news $/ 53770$.

18. Government.ru. [Электронный pecypc]. URL: http://government.ru/docs/26221.

19. Rosinfocominvest.ru. [Электронный pecypc]. URL: http://www.rosinfocominvest.ru/ about. 


\section{REFERENCES:}

Biktimirov M. R., Syuntyurenko O. V. (2017). VINITI RAN Tsifrovye informatsionnye resursy sovremennoy innovatsionnoy infrastruktury [VINITI RAS Digital Information Resources of Modern Innovation Infrastructure]. Nauch. i tekhn. b-ki. (1). (in Russian).

Government.ru. Retrieved from http://government.ru/docs/26221

Kazakova M.V., Pospelova E.A. (2017). Kachestvo infrastruktury kak odno iz ogranicheniy ekonomicheskogo rosta: sravnitelnyy analiz Rossii i stran mira [Quality of infrastructure as one of the limitations of economic growth: comparative analysis of Russia and the world countries]. Journal of International Economic Affairs. 7 (3). (in Russian). doi: 10.18334/eo.7.3.38071.

Kommersant.ru. Retrieved from http://www.kommersant.ru/doc/2896899

Kremlin.ru. Retrieved from http://www.kremlin.ru/events/president/news/53770

Lyashenko E.A. (2013). Metodologicheskie podkhody k ponyatiyu «tekhnoparkovaya struktura»[Methodological approaches to the concept of "techno-park structure"]. Issue subject Upravlenet. (5(45)). (in Russian).

Rosinfocominvest.ru. Retrieved from http://www.rosinfocominvest.ru/about

Yanik A.A., Popova S.M. (2014). Istoriya sovremennoy Rossii: Tsifrovaya infrastruktura mezhdistsiplinarnyh issledovaniy [The History of Modern Russia: The Digital Infrastructure of Interdisciplinary Research] M.: Izdatelstvo Moskovskogo universiteta. (in Russian). 
